\title{
OS MOVIMENTOS PROGRESSIVOS-REGRESSIVOS DA REFORMA PSIQUIÁTRICA ANTIMANICOMIAL NO BRASIL: UMA ANÁLISE DA SAÚDE MENTAL NA PERSPECTIVA DA PSICOLOGIA SOCIAL CRÍTICA
}

\author{
THE PROGRESSIVE-REGRESSIVE MOVEMENTS OF REFORM PSYCHIATRIC ASYLUMS IN \\ BRAZIL: AN ANALYSIS OF MENTAL HEALTH FROM THE PERSPECTIVE OF CRITICAL \\ SOCIAL PSYCHOLOGY
}

ALUÍSIO FERREIRA DE LIMA Ph.D., (UNIVERSIDAD FEDERAL DO (EARÁ - Brasil).

\begin{abstract}
RESUMEN
Este artículo tiene como objetivo analizar, desde una perspectiva de la psicología social, el campo de la salud mental en Brasil y los desafíos actuales para una eficaz desinstitucionalización y emancipación social. Con este fin, presentamos 1) el desarrollo de las ideas alienistas y la aplicación del manicomio como un dispositivo, teniendo en cuenta su uso como un instrumento de la administración social y la naturalización de la desigualdad; 2) presentamos los avances y retrocesos de la reforma de los asilos psiquiátricos, mostrando la transformación iniciada en 1987 con el Movimiento de Trabajadores de la Salud Mental y la importancia de la Ley 10.216/2001 que reorganizó la atención de toda la salud mental en Brasil y 3) a partir de la presentación de los problemas que enfrenta la reforma de los asilos psiquiátricos tomó nota de la persistencia de una racionalidad que impede la transformación radical de las relaciones entre los profesionales que se inscriben en el ámbito de la salud mental y las personas que reciben el diagnostico psiquiátrico. Concluimos este artículo argumentando que nuestro mayor reto es escapar de cualquier mirada nostálgica al pasado y un futuro sin esperanza, asumiendo todas las consecuencias con nuestra capacidad de pensar el presente.
\end{abstract}

PALABRAS CLAVE: Psicología Social, Salud Mental, Reforma Psiquiátrica en Brasil, Psicología de la Salud.

\section{ABSTRACT}

This article aims at analyzing, in a social psychology perspective, the course of mental health in Brazil and current challenges for effective desinstitutionalization and social emancipation. We demonstrate l) the development of alienists ideas and implementation the asylum as a tecnology used to instrument of social administration and naturalization of inequality, 2) the development and advances to psychiatric reform, showing the transformation initiated in 1987 with the Movement for Mental Health Workers and the importance of law 10.216/2001 in the reorganization of mental health care in Brazil and 3) the presentation of the problems faced by the reform psychiatric and the persistence of a rationality that difficult a radical transformation of relationships between professionals who are entered in the field of mental health and individuals undergoing psychiatric discourse. We conclude this article arguing that our biggest challenge is to escape any nostalgic look at the past and for a future without hope, assuming all the consequences with our ability to think this in present.

KEY WORDS: Social Psychology, Mental Health, Psychiatric Reform in Brazil, Health Psychology. 
O dispositivo manicomial como política de administração social: sobre a criação do alienado e a naturalização das desigualdades

Embora o manicômio somente apareça como dispositivo ${ }^{1}$ oficial de tratamento de indivíduos reconhecidos como loucos após o ano de 1822 no Brasil, não é nenhuma novidade que desde 1543 já existisse o isolamento desses indivíduos indesejáveis nas Santas Casas de Misericórdia e que em meados do século XVIII já dispunha de "casinhas de doidos" (Postel e Quétel, 2000, p. 462). Os manicômios efetivamente serão inaugurados durante 0 segundo reinado (18411889). São eles: o Hospício Dom Pedro II fundado em 1852, no Rio de Janeiro; em São Paulo, em 1852, estado em que a ofensiva da ciência com relação aos doentes mentais havia começado em 1848, com a lei provincial que visava criar um Hospício - somente inaugurado em 1852 na Avenida São João, que funcionou até 1864, quando foi transferido para uma chácara na Ladeira Tabatinguera; em Pernambuco, em 1861; na Bahia, em 1874 e no Rio Grande do Sul em 1884. No estado de São Paulo, em 1892, o doutor Franco da Rocha foi convidado pelo governo do estado a orientar os estudos sobre assistência aos alienados, resultando disso a construção do Hospício Juquery, concluída em 1903. Ainda no ano de 1903 , vota-se a primeira lei que regulamenta as internações, que passaram a ser efetivadas somente se o indivíduo passasse por um exame de seu estado mental. A mesma lei criou a divisão entre 0 encarceramento dos doentes mentais e criminosos, tornando necessárias as construções de novos hospícios para alienados criminosos e para alienados delinquentes (Postel e Quétel, 2000, p.467). A diferença aparece na práxis, na concepção de alienação e no método de tratamento dos indivíduos.

Para intelectuais brasileiros desse período, como Brandão (1918), por exemplo, a teoria da degenerescência desenvolvida por Morel teórico que relacionava a alienação diretamente com a herança genética, a raça, a higiene e 0 clima -, servirá para sustentar a diferença entre os seres humanos, dividindo-os em inferiores e superiores, em um momento

\footnotetext{
1 De acordo com Agamben (2009, p. 40) dispositivo pode ser entendido como "qualquer coisa que tenha de algum modo a capacidade de capturar, orientar, determinar, interceptar, modelar, controlar e assegurar os gestos, as condutas, as opiniões e os discursos" dos indivíduos.
}

histórico no qual a teoria de Kraepelin - que havia se formado na escola organicista $e$ neuropatológica alemã e proposto classificações sucessivas sobre doenças mentais em seu "Tratado de Psiquiatria" - era hegemônica mundialmente. Aliás, embora tenham ocorrido algumas alterações de cunho jurídico, a concepção de alienação hegemonicamente adotada era a de Teixeira Brandão. A teoria da degenerescência teve um duplo efeito de autorizar com suas hipóteses a reorientação do alienismo e a formulação de um novo projeto de profilaxia a partir do asilo no Brasil.

A influência dessa nova ideologia dominante pode ser vista no caso da criação da Liga Brasileira de Higiene Mental, em 1923, na cidade do Rio de Janeiro, por Gustavo Riedel. A instituição trabalhava com os aportes da psicologia e mantinha um laboratório e um "Seminário Brasileiro de Psicologia" que se reunia semanalmente e anualmente organizava as "Jornadas Brasileiras de Psicologia". 0 objetivo inicial das Ligas era pensar a melhoria da assistência ao alienado. Contudo, a partir de 1926, esse objetivo foi cedendo lugar para a ideologia eugênica, a profilaxia e a adaptação dos indivíduos por meio da educação e da prevenção, que acabou por reduzir as Ligas a ambulatórios, "onde eram atendidos neuróticos e psicóticos menos graves, que recebiam, especialmente, tratamentos medicamentosos" (Yahn, 1955, p.40).

Nina Rodrigues, um do mais respeitados intelectuais brasileiros da época defenderá que os indivíduos que não se adequassem às terapias adaptativas deveriam ser vistos como ameaças sociais e retirados da sociedade, independentemente de sua raça. A própria alienação era entendida a partir dessa articulação entre pensamento primitivo e inadaptação à sociedade. As proposições de Nina Rodrigues publicadas desde $\mathrm{O}$ alienado no direito civil brasileiro: apontamentos medicolegaes ao projecto de código civil, em 1901, fortalecerá a arbitrariedade de interpretação em relação ao que seria considerado crime, imputando ao criminoso a etiologia da criminalidade associada à ideia da mentalidade primitiva, isentando assim, a influência das condições sociais na construção do criminoso, ao mesmo tempo que a sociedade era entendida como vítima do indivíduo criminoso, 0 que referendava a exclusão dos degenerados e 
a regeneração dos indivíduos. Sua influência será explícita na medicina social, psicologia forense e criminal, de autores como Oscar Freire, Flámínio Favero, Almeida Junior, Pacheco e Silva e, principalmente, em Arthur Ramos. Este último autor, considerado um dos fundadores do campo da Psicologia Social brasileira, foi discípulo de Nina Rodrigues e um dos mais importantes e veementes defensores da teoria da degenerescência no Brasil, publicando várias obras que procuravam enfocar a inferioridade racial e a degeneração psíquica dos pobres, assim como as formas de expressão afro-brasileiras.

$\mathrm{Na}$ sociedade em que o discurso técnicocientífico exigia a implementação da disciplina que garantiria a ordem e o progresso, a alienação tornou-se um conceito útil para explicar a ruptura do equilíbrio individual e coletivo. Conceito que, por sua vez, inicia o período de ampliação da ação do Estado na esfera privada que seguirá deste período até meados da Segunda Guerra Mundial. O tratamento moral, por sua vez, passou a ser utilizado como intervenção científica para 0 controle e a correção dos indivíduos não convencionais, repetindo a história dos países europeus e dos Estados Unidos. As causas da alienação passam a ser relacionadas a fatores predisponentes - o clima, a sexualidade, a idade, o temperamento, a profissão e o modo de vida - e a causas determinantes, ou seja, fatores físicos (comportamentos hereditários de distúrbios patológicos) e emocionais (devido a problemas familiares).

Seguindo a influência norte-americana, 0 Brasil, a partir de 1960, mais precisamente após a publicação do Decreto 49.974 , de 21 de janeiro de 1961, promove uma nova reforma psiquiátrica. A novidade no decreto está na inversão da internação do alienado, do psicopata, como elemento indispensável para a ordem social, para desse momento em diante, a desinternação progressiva desses indivíduos. Em outras palavras, efetivamente essa reforma apenas promoveu a substituição do termo "doença mental" por "saúde mental" e efetuou um upgrade na tecnologia psiquiátrica tradicional, que poderia agora abrir as portas da instituição psiquiátrica para que outros saberes se tornassem parceiros. Com a adoção da epidemiologia como referência principal na elaboração das políticas (Brasil, 1961, Art. 83), abandonam-se as preocupações com a ordem pública - tão presentes nas ideias e leis de períodos anteriores e que reduziam os problemas políticos-sociais-econômicos aos atributos individuais específicos do povo brasileiro -, e passa-se a identificar os casos particulares "típicos", o que possibilita identificar - impacto das ações de saúde mental da população, que passaria a ser cada vez mais medicalizada. Isso mostra que o projeto de desinstitucionalização - que na verdade foi apenas de desinternação, ao passo que não se questionava a instituição psiquiátrica proposta a partir de 1961 no Brasil, não foi um resultado a posteriori de nenhum movimento social, pelo contrário, foi a priori mais uma estratégia de ajuste político-econômico que se mostrou como um retrocesso à lógica manicomial.

Esperava-se que o Código Nacional de Saúde pudesse garantir a redução das internações psiquiátricas e ampliar a assistência à comunidade, e que, para tanto, multiplicar-se-iam os equipamentos para-hospitalares e anexos psiquiátricos nos hospitais gerais. $\mathrm{Na}$ prática, ocorre 0 inverso; paradoxalmente, ocorrerá justamente nesse período a grande expansão dos manicômios no Brasil. O Brasil, que no imediato pós-guerra estava capitalizado, forneceu as condições necessárias para que dois documentos datados de $1946 \mathrm{e}$ 1947 fossem contemplados e beneficiassem empreendedores privados. [...] Em 1941, em meio à Segunda Guerra Mundial, existiam 65 hospitais psiquiátricos no Brasil (31 pertenciam à rede pública e 34 à privada). Após o Plano Salte, mais precisamente em 1961, existiam 140 hospitais (54 públicos e 86 privados). Nos 10 anos que seguiram, em que ocorreu a maior privatização dos serviços de saúde da história brasileira, em todo território nacional existiam 340 hospitais (63 públicos e 277 privados). Entre os anos de 1971 e 1981 nenhum hospital público foi aberto, ao passo que 0 número de hospitais psiquiátricos 
privados passou de 277 para 362 (Lima, 2010, p. 95-97).

Fica cada vez mais explícito o fato de que a história da consolidação da saúde mental no Brasil é uma história de reformas manicomiais iniciadas concretamente desde 0 início do século XX e que após 1960 seguiu duas frentes: o fortalecimento dos manicômios privados e 0 aumento da intervenção psiquiátrica na comunidade, com fortes tendências a psiquiatrização do social, em que o psiquiatra deve responsabilizar-se, treinar os agentes nãoprofissionais, tais como: vizinhos, agentes religiosos, líderes comunitários etc. Sendo assim, vemos que mesmo o conceito de saúde mental surge associado a um processo de adaptação do social, apontando um padrão ampliado de anormalidade, do mesmo modo como ocorreu nos Estados Unidos (Szasz, 1994). Entretanto, também verificaremos nesse período que concomitantemente às tentativas de ajustamento dessa comunidade imaginada (Anderson, 2008), que não se restringiu apenas à saúde mental, mas sim a toda política nacional, surgirão formas de resistência advindas tanto de movimentos universitários como dos movimentos populares: as minorias mostram-se como maiorias silenciosas.

Por falar em escolhas, no que se refere à própria concepção de democracia, defendida como uma das bandeiras que justificavam tal reforma psiquiátrica, se torna evidente que 0 caminho seguido por essa política de identidade foi 0 de abrir mão da eliminação da desigualdade e luta por redistribuição econômica - tão explícita nos casos em que 0 diagnóstico psiquiátrico foi utilizado na história da doença mental no Brasil -, e assumir a bandeira do reconhecimento da diferença, da anulação da degradação e desrespeito, garantindo emprego para os especialistas envolvidos com a saúde mental. Santos (2002) acredita que a adoção dessa perspectiva político-social tem uma relação direta com a herança política da ditadura que vivenciamos e possibilitando 0 aprofundamento de processos iniciados a partir de 1930.

A ditadura militar, além de consolidar novas estruturas sócio-econômicas de poder, produziu um modelo de Estado que no início da década de oitenta se encontrava já em profunda crise. Em meados da década, a transição democrática avançou, pondo fim ao modelo de dominação política, mas não confrontou as estruturas de poder econômico e social nem deu prioridade à reforma do Estado. Foi nesse contexto que as elites conservadoras cavalgaram com êxito a transição democrática, aproveitando e reforçando a crise do Estado para entregar o país à nova ortodoxia neoliberal onde vieram as novas oportunidades para reproduzir seu poder (Santos, 2002, p.13).

A assunção dessa proposta conciliadora tornarse-á mais evidente a partir de 1978, quando será fundado o Movimento de Trabalhadores em Saúde Mental - MTSM, que articulou as reivindicações trabalhistas, com 0 discurso humanitário. Esse movimento fortaleceu-se nos anos seguintes e liderou os acontecimentos que fizeram avançar até seu caráter fundamentalmente antimanicomial (Amarante, 1995, p.492). As discussões trazidas por esse movimento de trabalhadores estavam voltadas para a garantia de direitos dos pacientes, 0 aperfeiçoamento e universalização dos instrumentos utilizados até então, ou seja, 0 direito à saúde como questão político-social.

As experiências "bem sucedidas" realizadas pelo Programa de Saúde Mental de Santos e pelo Centro de Atenção Professor Luiz da Rocha Cerqueira, em São Paulo, são vistas como marcos inaugurais da última reforma psiquiátrica que vivenciaríamos até o presente momento. No caso do Programa de Saúde Mental de Santos, que surge após a intervenção motivada pelas denúncias (comprovadas) de mortes, superlotação, abandono e maus-tratos, veremos que surgirão os Núcleos de Atenção Psicossocial - NAPS, e que será uma das muitas experiências documentadas e discutidas em dissertações de mestrado e doutorado a partir de 1988 (Leal, 1994; Koda, 2002). Nessa proposta o serviço de atendimento é realizado, em geral, durante o dia e à noite 0 indivíduo volta para casa, o que torna muito menos custoso sua manutenção. Esse atendimento possibilita que o paciente compareça todos os dias da semana se necessário e tenha um acompanhamento multiprofissional.

Com a difusão do "sucesso" cada vez maior desse novo modelo as condições para a concretização do movimento pela "nova" 
Reforma Psiquiátrica, de vertente antimanicomial, tornam-se possíveis. Dois eventos ocorridos em 1987, inclusive, serão o marco dessa consolidação, são eles: a । Conferência Nacional de Saúde Mental e o II Encontro Nacional dos Trabalhadores em Saúde Mental. Esse último é planejado durante a I Conferência, após a constatação de que a perspectiva sanitarista de incorporar as propostas reformistas nas políticas do período vinha sofrendo a resistência da rede hospitalar privada.

Vale reforçar aqui que a Lei 10.216, aprovada em 2001 (Brasil, 2004), tornou finalmente possível a execução do plano que, como vimos, já era visualizado em 1961, o que é possivel observar no desenvolvimento que a "nova" reforma psiquiátrica antimanicomial terá a partir do momento em que a nova lei começou a vigorar. No mesmo ano, por exemplo, foi convocada a III Conferência Nacional de Saúde Mental (Brasil, 2002), que segundo o relatório elaborado ao final do evento, as etapas municipal e estadual envolveram cerca de 23.000 pessoas, e a etapa final contou com 1.480 delegados, entre representantes de usuários, movimentos sociais, familiares e profissionais. Com o evento, o novo ciclo da reforma psiquiátrica brasileira é fechado, profissionais, pesquisadores, usuários $\mathrm{e}$ familiares, assumem esse modelo como o ideal a ser buscado. Em 2004, realiza-se o primeiro Congresso Brasileiro de Centros de Atenção Psicossocial, em São Paulo, que segundo o Ministério da Saúde reuniu dois mil trabalhadores e usuários (Brasil, 2005).

No âmbito jurídico, a Lei 10.216/01 também pode ser considerada um marco da retomada da autonomia e hegemonia psiquiátrica, uma vez que a partir dessa lei esta instituição volta novamente a ter leis e portarias específicas para sua organização e financiamento. Mais tarde, inclusive, serão criadas linhas específicas de financiamento pelo Ministério da Saúde para os serviços abertos e substitutivos ao modelo manicomial, assim como serão criadas novas normas para fiscalização e classificação dos hospitais psiquiátricos. Isso foi um avanço do ponto de vista da organização e distribuição de recursos, pois até 1992, por exemplo, o país tinha "208 CAPS [Centros de Atenção
Psicossocial], mas cerca de $93 \%$ dos recursos do Ministério da Saúde para a Saúde Mental ainda [eram] destinados aos hospitais psiquiátricos" (Brasil, 2005, p.7). E, finalmente, na esfera acadêmica, por sua vez, o crescimento das pesquisas que se voltaram para o desenvolvimento de tecnologias para saúde mental, desinstitucionalização, crítica aos hospitais psiquiátricos etc., seguiu o mesmo movimento de expansão dos serviços substitutivos, uma vez que apos a aprovação da Lei 10.216/10 a produção de teses nesse campo de conhecimento aumentou em mais de 100\% (Cf. Lima, 2010, p. 116-120).

A reforma psiquiátrica antimanicomial como proposta emancipatória: sobre a negação e 0 consentimento das práticas manicomiais

Como pode ser observado ao longo de nosso texto, o Brasil passou por várias reformas desde a implementação da lógica manicomial como dispositivo de tratamento do alienado. Também evidencia-se que desde meados de 1960 surgiram alguns movimentos sociais, que foram organizados efetivamente a partir do final da década de 70 e início da década de 80 , que questionaram as condições de cuidado e a validade dos diagnósticos, resultando no que é chamado de reforma psiquiátrica antimanicomial que tinha como pressuposto a desinstitucionalização. Aliás, no que se refere a essa reforma psiquiátrica antimanicomial considera-se que presenciamos atualmente no Brasil 0 terceiro momento de seu desenvolvimento, valendo a pena retomá-los e aprofundá-los.

0 primeiro momento da reforma psiquiátrica brasileira, que toma como marco inaugural a fundação, em 1978, do Movimento de Trabalhadores em Saúde Mental (MTSM), foi 0 instante de questionamento da política de saúde mental desenvolvida no Brasil, que - embora desde 1961 preconizasse os serviços de tratamento em saúde mental situados nos territórios - continuava financiando massivamente os asilos privados desde 1946, instituições que, por sua vez, sofriam várias críticas por serem espaços de segregação pessoal e aniquilação subjetiva (Foucault, 1991; Foucault, 2006; Goffman, 1974; Laing, 1975; Szasz, 1977; Szasz, 1979). Sendo que o que 
caracterizava os pacientes psiquiátricos, "alienados", "loucos", "doentes mentais", etc., era o fato de serem "destituídos de seus direitos e poderes para classificarem-se a si ou a outros, e terem sido tratados unicamente como objetos de classificação pela sociedade" (Szasz, 1977, p. 57) e, especialmente, por especialistas.

Assume-se, com o questionamento da política de saúde mental desse período, 0 desafio à superação dessas instituições que eram hegemônicas no país. As discussões estavam voltadas para a garantia de direitos dos pacientes, o aperfeiçoamento e universalização dos instrumentos utilizados até então, ou seja, 0 direito à saúde como questão político-social. Como foi assinalado anteriormente, as experiências pioneiras, bem sucedidas e isoladas, como o Programa de Saúde Mental de Santos e pelo Centro de Atenção Professor Luiz da Rocha Cerqueira, no estado de São Paulo, associação com a Saúde Pública no Rio Grande do Sul, as incursões no Rio de Janeiro, serão utilizadas como referência para a proposta de uma sociedade sem manicômios na I Conferência Nacional de Saúde Mental e no II Encontro Nacional dos Trabalhadores em Saúde Mental.

O segundo momento da reforma psiquiátrica brasileira, por sua vez, se concretizou com criação do Movimento de Luta Antimanicomial, que se espalhou pelo país com a sustentação de um discurso "alternativo" ao sistema manicomial a partir da invenção de novos dispositivos e tecnologias de cuidado, substituindo a clínica fechada por instrumentos abertos, diversificados, de natureza comunitária, que garantiriam a desinstitucionalização. É importante frisar que embora fosse reivindicado - fechamento dos hospitais psiquiátricos e abertura de serviços substitutivos, a desinstitucionalização proposta pelo Movimento de Luta Antimanicomial não se resumia à desospitalização. Como bem assinalou Basaglia (2005), autor de forte influência no Brasil nesse período, 0 ato político que deveriam assumir todos os envolvidos no movimento antimanicomial deveria ser 0 da reviravolta institucional e científica, que recusaria o "ato terapêutico como resolutivo de conflitos sociais, que não podem ser superados mediante a adaptação de quem os sofre" (Basaglia, 2005, p.105). Nesse sentido, a desinstitucionalização psiquiátrica se concretizaria pela subversão da situação científica esclerótica da psiquiatria clássica, "saída da referência dos paradigmas reducionistas, simplistas, vulgares e oitocentistas, constituídos para controlar, de modo rudimentar e grosseiro, as classes subalternas e todas as formas de desvio, em um momento em que era necessário um rápido processo de acumulação capitalista" (Rotelli, 2006, p. 301).

$\mathrm{Na}$ virada do século $\mathrm{XX}$, presencia-se 0 terceiro momento da reforma psiquiátrica, possibilitado pela paulatina entrada de militantes do movimento antimanicomial no interior dos aparelhos de Estado. Com a aprovação da Lei $n^{0} 10.216$ de 6 de abril de 2001 (Brasil, 2004), que contemplava a Declaração de Caracas de 14 de novembro de 1990, o que até então era uma proposição alternativa à política de saúde mental desenvolvida, transforma-se, nesse momento, em uma política de Estado. Em outras palavras, aquilo que era oposição ao sistema tornou-se posição do sistema, apoiada em uma lei federal que organizaria a saúde mental no país e concretizaria uma complexa e sistemática política pública embasada em leis, portarias ministeriais, leis municipais $\mathrm{e}$ estaduais, etc.

Certamente que mesmo com a publicação de uma Lei Federal, portarias de regulamentação e apoio governamental, 0 desafio assumido pela reforma psiquiátrica era e continua a ser grandioso. Afinal, além dos problemas inevitáveis que seriam encontrados em uma política de redução de leitos dos manicômios privados - política que transformaria radicalmente a forma oficial de tratamento destinada à doença mental no Brasil desde a publicação do Decreto n. ${ }^{0} 1132$ em 1903 (Brasil, 1903) -, a reforma psiquiátrica ainda teria que lidar com três outras questões: 1) construir alternativas e sustentar uma rede substitutiva ao modelo manicomial existente; 2) criar novos dispositivos clínicos e terapêuticos orientados pela noção de cuidado e promoção da autonomia; e 3) garantir a desinstitucionalização por meio da promoção de cidadania e ampliação dos espaços de sociabilidade, que significa direito à assistência social (moradia, comida, vestimentas), direito a possibilidades mínimas de sobrevivência e de reconhecimento como sujeito de direito. 
E de fato, no que se refere à redistribuição de recursos e ampliação dos serviços substitutivos, percebe-se que o Estado tem conseguido garantir o projeto de reforma psiquiátrica. Os gastos com os serviços substitutivos têm chegado a ultrapassar os destinados para os hospitais psiquiátricos. Se em 1997, por exemplo, eram gastos $97,14 \%$ dos recursos com os hospitais psiquiátricos e $6,86 \%$ com os serviços extra-hospitalares, no ano de 2006, foram gastos $48,67 \%$ dos recursos com os hospitais psiquiátricos e $51,33 \%$ com os serviços extra-hospitalares. 0 número de Centros de Atenção Psicossocial - CAPS cresceu entre 2003 e 2006, de 500 para 1011, aumentando em mais de $100 \%$ em apenas três anos. Enquanto isso, no mesmo período, o número de leitos em Hospitais Psiquiátricos diminuiu mais $22 \%$, caindo de 48 mil para 39 mil, ou seja, em termos absolutos, entre os anos de 2003 e 2006, foram reduzidos 11.826 leitos no Brasil e foram instalados 500 CAPS. Ao mesmo tempo foram instalados, no período de 2002 a 2007, 2,4 mil leitos psiquiátricos em Hospitais Gerais em todo o país (Brasil, 2007).

É certo que existe atualmente um ambiente favorável para o estabelecimento de práticas alternativas e inovadoras. Todavia, ainda persistem nos serviços a manutenção de práticas tradicionais de diagnóstico e tratamento, que Machado e Lavrador (2001), identificaram como "desejos de manicômio" e que se referem especificamente ao processo de aprisionamento dos técnicos às categorias tradicionais que configuram o estereótipo do louco, que em sua materialização cotidiana se expressam como formas de reconhecimento perverso (Lima, 2010) e no máximo tentam resolver problemas de ordem social com a administração de medicamentos (Szasz, 2008).

Basta observar o consumo absurdo de medicamentos controlados no Brasil, oferecidos pelos serviços de saúde mental como se fossem aspirinas para dor de cabeça. Na pesquisa realizada por Ana Cláudia Passos, que verificou a utilização de psicofármacos em um município do estado do Ceará ficou evidenciado que a média de consumo de medicamentos dos usuários do CAPS desse município era de 1,5 por pessoa. A maioria das pessoas $(78,3 \%)$ utilizavam de forma contínua os medicamentos e a maioria sequer havia sido informada dos riscos de utilizá-los por tempo prolongado $(73,3 \%)$. Dentre os tipos de medicamentos utilizados, 36,5\% faziam uso de ansiolíticos e $31,5 \%$ antidepressivos. Quanto à aquisição desses medicamentos, $41,6 \%$ foram adquiridos na farmácia do CAPS e $24,3 \%$ compraram. Os principais motivos que geraram o consumo dos psicofármacos foram: "nervosismo", "insônia" e "depressão" causados por desemprego e problemas afetivos (Passos, 2008).

Sem contar que o próprio modelo de financiamento dos serviços, baseado na produtividade, favorece a necessidade de manobras que possibilitam os serviços atingirem o teto disponível para o serviço (dentre eles 0 diagnóstico indiscriminado para problemas de ordem social), enquanto que impossibilitam a implementação de projetos de intervenção que extrapolem os muros dos CAPS e demais serviços substitutivos. $O$ usuário dos serviços substitutivos, como já assinalava Thomas Szasz ainda no final dos anos 60, tem seu reconhecimento reduzido à condição de paciente "membro de um grupo e nunca como um indivíduo" (2008, p. 51).

A reforma psiquiátrica antimanicomial brasileira como um problema para a Psicologia Social: sobre a regulação e as possibilidades de emancipação

Embora a reforma psiquiátrica atual se encontre em pleno desenvolvimento, muitos problemas ainda persistem e ultrapassam o desmonte dos hospitais psiquiátricos. Afinal, como já era evidente no discurso antimanicomial e na proposta de desinstitucionalização, somente seria possível superar a lógica manicomial se assumíssemos a subversão da própria concepção de instituição psiquiátrica como saber hegemônico. Isso requer assumir radicalmente um projeto de desinstitucionalização que ultrapasse as fronteiras sanitárias e se transforme em uma "luta política, teórica e prática que visa a articular uma rede comunitária de cuidados, englobando diferentes serviços substitutivos ao manicômio, que se conecte também a outros espaços da cidade" (Dimenstein, 2009, p. 8). 
As pesquisas acerca dos problemas com os manicômios do início do século XX no Brasil e dos CAPS, CAPSad (especíicos para tratamento dos usuários de álcool e outras drogas) e demais serviços substitutivos atuais (Koda, 2002; Queiroz, 2005; Nader, 1990) mostram que as formas de intervenção no projeto proposto pela instituição psiquiátrica continuam produzindo a estigmatização e a medicalização dos indivíduos, o que leva a intuir que a reforma psiquiátrica tem se dado apenas em nível instrumental, burocrático.

Ao que parece, a crítica manicomial se dissolve ao longo dos anos; os focos de ataque se dirigem a alvos secundários. Em todas, a ideia de necessidade de reforma psiquiátrica permanece, tudo se resume a transformações de ordem instrumental. Talvez aí esteja a raiz do problema: o conceito de reforma. A libertação deveria ser das correntes da instituição psiquiátrica, instituição que, como vemos, ainda é a base na formação do conhecimento científico para lidar com formas não convencionais de interação. Nunca no Brasil se propôs uma "revolução" ou "emancipação" psiquiátrica (Lima, 2010, p.114), mas sim, ajustes nos dispositivos, que como bem ensinou Agamben (2009, p. 40) podem ser entendidos como "qualquer coisa que tenha de algum modo a capacidade de capturar, orientar, determinar, interceptar, modelar, controlar e assegurar os gestos, as condutas, as opiniões e os discursos" dos indivíduos.

A pesquisa de Lima (2010) assinalou que 0 longo dos anos com as transformações teóricopolíticas, somou-se à identidade pressuposta do paciente doente mental, proposta pela instituição psiquiátrica, uma identidade pressuposta do cidadão doente mental, pelos militantes da saúde mental, que culminou no desenvolvimento da política de saúde mental brasileira, que vivenciamos atualmente, a qual assume uma ideologia em sustenta que 0 produtor da desumanização do doente mental é - manicômio e que a solução para essa desumanização está na ampliação, a partir de dados demográficos, as instituições substitutivas, isto é, dos novos dispositivos de controle que promoverão a inclusão do louco na sociedade.

Se se considerar os elementos históricos trazidos até agora não parece incorreto afirmar que a persistência da hegemonia psiquiátrica tem relação com a adoção de uma racionalidade instrumental que passa a ser utilizada como um instrumento útil para os profissionais da saúde mental, que acreditam possuir, sob forma de monopólio, o único conhecimento verdadeiro e legítimo sobre a questão da saúde e da doença, além de acreditarem estar investidos de uma autoridade científico-social que os coloca como militantes especialistas capazes de prescrever as melhores formas de inclusão daqueles que eles mesmos carimbam com 0 diagnóstico excludente. Não se quer dizer aqui que não ocorreram mudanças qualitativas, pelo contrário, a reforma psiquiátrica brasileira atual é mais humanizadora que a lógica manicomial sustentada até a publicação da Lei 10.216/10.

De fato 0 que se quer afirmar é que ainda sustentamos muitas vezes uma práxis reiterativa, que não produz uma mudança radical na realidade presente, "não transforma criadoramente, ainda que contribua para ampliar a área do já criado e, portanto, multiplicar quantitativamente uma mudança qualitativa produzida. Não cria; não faz emergir uma nova realidade humana" (Vasquez, 1977, p. 258). Ainda baseados nos elementos históricos é possível inferir, inclusive, que atualmente 0 discurso que descreve a identidade pressuposta do doente mental continua sendo monopolizado pela instituição psiquiátrica, cujo projeto encontra-se muito bem estruturado e alinhado às necessidades de administração capitalista. Aqui aparece de forma explícita o ponto de descontentamento com a proposta da reforma psiquiátrica antimanicomial e a postura de grande parte dos "especialistas" da saúde mental que não assumem de fato uma postura crítica frente ao seu objeto.

Não é nenhuma novidade que os especialistas têm fechado os olhos em momentos oportunos - diagnóstico, faturamento dos serviços e medicalização para o fato de que cada vez que os psiquiatras, laboratórios e/ou centros de pesquisa criam uma nova regra de saúde mental, "criam uma nova classe de indivíduos mentalmente doentes - assim como, cada vez que os legisladores promulgam uma nova lei restritiva, criam uma nova categoria de delinqüentes" (Szasz, 1984, p. 27). E que o mesmo ocorre da parte dos diagnosticados, que quando cumprem as 
prescrições dadas pelos técnicos da saúde mental, o fazem porque não querem ser penalizados pelo não cumprimento, ou porque consideram justas, ou acreditam que devem respeito às autoridades que tanto dizem que os defendem, ou porque entendem que se não se submeterem à lógica dominante serão assombrados pelo fantasma do manicômio, demônio persistente que aparece como única alternativa (em retrocesso) para o modelo de reforma atual. Além do fato que, uma vez que atualmente a doença mental é uma forma de existência que possibilita reconhecimento social e, principalmente, acesso à renda, nega-se também uma pactuação perversa entre a instituição substitutiva e o usuário do serviço.

Pesquisas recentes como a de Kirillos Neto (2007), realizada em São Paulo, analisam os efeitos da circulação do discurso psiquiátrico em serviços substitutivos de saúde mental e nos mostra - se referindo ao fenômeno de adesão a práticas psicofarmacológicas -, que tudo se passa como se ao aceitar a narrativa da inclusão oferecida pelo discurso da saúde mental, "ao conformar seus paradoxos aos próprios paradoxos da formação delirante, 0 usuário aceitasse também e, agora, mais docilmente, 0 consumo de substâncias 'antipsicóticas'” (Kirillos Neto, 2007, p. 165), encaradas agora como um direito individual e/ou um desejo pessoal e não mais algo a ser resistido.

Numa outra face do mesmo problema, vemos que o Estado aparece e permanece como agente de facilitação do capitalismo tardio, cujas estratégias transformaram-se ao longo dos tempos, indo das técnicas violentas de contenção para a neutralização das possibilidades de organização social dos indivíduos, que explicitariam que o problema não pode ser reduzido à humanização no tratamento do doente mental. Essas estratégias de contenção e neutralização, aperfeiçoadas desde o início de 1960, por sua vez, desembocam num funcionamento sintomático em tempos de um capitalismo cuja busca de legitimação tenta, ao mesmo tempo, regular as formas de interação social e o desenvolvimento da autorregulação, de um lado, e estimular 0 consumo e satisfação irrestrita, de outro.
Fica evidenciado também que partir da política de oferta de novos serviços substitutivos, baseados na expansão a partir de dados demográficos e não necessariamente das demandas locais, o Estado tem atraído cada vez mais simpatizantes, principalmente profissionais das áreas "psi", que enxergam nos espaços substitutivos possibilidades de atuação profissional garantidas por portarias de regulamentação do Ministério da Saúde. Sob o deslocamento da raiz do problema da reforma, 0 Estado tem promovido diversos cursos de capacitação dos profissionais, fóruns, congressos, material bibliográfico, áudio-visual e virtual, que socializa 0 discurso médico e populariza de forma problemática a saúde mental, como explica Sérgio Aragaki (2006, p.36):

Essa popularização da área, longe de permitir melhor condição de acordos entre profissionais de saúde e seus pacientes, em busca de melhores possibilidades de conviver, reafirmam àqueles que dessa área se utilizam, os seus lugares de poder e de controle social. Todos os comportamentos e sentimentos humanos podem ser em algum momento sinais de algo que não está bem, que há um processo patológico já instalado ou se instalando. Tudo pode ser alvo de tratamento. E tratamento inclui de forma essencial a medicalização.

O Estado também tem recebido apoio e apoiado sem reservas 0 Movimento da Luta Antimanicomial, seja porque muito dos representantes do governo são antigos militantes, seja porque 0 apoio às suas políticas representa (pelo menos hipoteticamente) uma melhoria nos aparelhos públicos de cuidado, garantia de medicamentos, previdência e aumento de empregos para os técnicos. Embora de forma concreta vejamos o doente mental sendo reconhecido apenas como produto, contribuinte ativo e consumidor de produtos (principalmente medicamentos) $\mathrm{e}$ serviços, representando uma cidadania fraca que o torna usuário (dependente) do serviço de saúde mental, para somente depois promover sua reabilitação e inclusão na comunidade (Brasil, 2003), ou como Habermas (1990) 
compreende, para somente depois incorporar, a partir do controle de comportamento, esses indivíduos no mercado.

Mas e se a negação da persistência do discurso psiquiátrico no discurso da saúde mental refletir na verdade uma tentativa de riscar da memória coletiva sua culpa pela construção do inimigo comum: o manicômio? Como concretizar uma reforma psiquiátrica antimanicomial se a concepção de loucura desenvolvida pela instituição psiquiátrica e mantida pelos técnicos da saúde mental ainda persiste na sociedade e esvaiu-se para além dos muros do próprio manicômio, e como escreve Habermas (2002 p.345), serve de instrumento sistêmico de administração social? Como libertar o Outro se ele é por princípio o objeto necessário de um saber de liberdade? Como fazê-lo reconhecer-se em um saber do qual ele não é, em primeira instância, produtor, mas reprodutor?

Não é simples responder questionamentos tão complexos, afinal, como se pode perceber, embora apresente inevitavelmente avanços em nível local e nacional, a reforma psiquiátrica antimanicomial ainda apresenta diversos desafios e impasses para a efetivação de uma rede de atenção em saúde mental. Em um país periférico e pós-colonial como o Brasil, onde a naturalização da desigualdade social pode ser mais adequadamente percebida como consequência do desejo de modernização e importação dos ideais eugenistas e positivistas iniciados no século XIX (Lima, 2010), a construção de um sistema assistencial em saúde mental inspirado nos reclames da desinstitucionalização psiquiátrica exige muito mais do que a implantação de políticas e projetos terapêuticos substitutivos.

Entretanto, é preciso que se desenvolva uma reflexão crítica de todo o processo que possibilite encontrar uma maneira de delinear com clareza quais são os desafios específicos que este horizonte de transformação enfrenta nas condições de nosso país. Como bem assinalou Martin-Baró, ainda no início dos anos 1980, a Saúde Mental na perspectiva antimanicomial deixa de ser um problema terminal e se converte em um problema fundante de nossas sociedades.
No se trata de un funcionamiento satisfactorio del individuo; se trata de un carácter básico de las relaciones humanas que define las possibilidades de humanización que se abren para los miembros de cada sociedad y grupo. En términos más directos, la salud mental constituye una dimensión de las relaciones entre personas y grupos más que un estado individual, aunque esa dimensión se enraíce de manera diferente en el organismo de cada uno de los individuos involucrados en esas relaciones, produciendo diversas manifestaciones (síntomas) y estados (síndromes). (Martín-Baró, 1984)

A citação de Martín-Baró reforça a ideia de que a saúde mental é uma questão que não deve ser pensada de forma posterior à ideia de adoecimento mental. Novamente vale dizer que não se trata de criarmos serviços e tratamentos que possam garantir um funcionamento satisfatório dos indivíduos, mas de criarmos e administrarmos uma cultura de humanização que possibilite 0 acesso de todos os indivíduos à esfera pública. Essa análise, aliás, não é nova, as denúncias realizadas pelos trabalhos de Goffman (1974) sobre a carreira moral dos doentes mentais; de Szasz (1979) sobre a utilização da ideologia psiquiátrica e da internação como processo de desumanização e desresponsabilização humana; de Basaglia (2005) sobre associação da doença mental com a improdutividade; e de Foucault (2006) sobre as práticas de saber-poder que se apropriam dos sujeitos por meio do discurso psiquiátrico, foram importantes referenciais para a compreensão de que 0 problema dos manicômios não era apenas seus muros altos, portões e cadeados, mas sua condição como objeto de estigmatização, isolamento, exclusão, condenação moral, tortura e aniquilação física. O manicômio, como instituição de tratamento do anormal, desse modo, não pode ser resumido à sua estrutura física, pois como bem assinalou Castoriadis (2007, p.159), uma "instituição é uma rede simbólica, socialmente sancionada, onde se combinam em proporções e em relações variáveis um componente funcional e um componente imaginário". Uma instituição é, portanto, também constituída e sustentada por determinadas linguagens partilhadas entre as pessoas que a compõem e por determinadas 
formas como se relacionam no espaço institucional.

Lembremos que a criação da cultura manicomial somente foi possível no Brasil após um longo processo de colonização do imaginário social, que delimitou o que seria normal e o que seria patológico (Lima, 2010). Essa colonização se concretizou a partir da vinculação das grandes narrativas criadas por intelectuais brasileiros que ligavam a ideia de normalidade com 0 progresso e que paulatinamente foram se conectando com 0 capitalismo e os mecanismos de reprodução social desde 0 início do século XX. No Brasil a associação normalidade e progresso, além de garantir a criação dos asilos, também foi responsável pela reconfiguração de uma esfera pública, que se tornou cada vez mais incapaz de suportar a diferença, apreendida como doença.

Em um cenário como esse parece evidente que devemos assumir que o que é novo na nova reforma psiquiátrica iniciada em 1987 são as estratégias de governabilidade e seus dispositivos, uma vez que o interesse agora se transfere do indivíduo problemático que não se alinhava a lógica da produção e a ordem, tal como propunham Brandão e Nina Rodrigues no auge do eugenismo brasileiro, e se dirige a grupos inteiros, comunidades, que devem agora ser incorporados a lógica de consumo neoliberal. Enquanto não considerarmos isso estaremos correndo o perigo de reproduzir a lógica da negação e consentimento frente ao projeto da instituição psiquiátrica, ficando impedidos de pensar em uma outra leitura alternativa à alternativa encontrada atualmente para lidar com as doenças mentais. Enquanto se focar nossa atenção apenas para o efeito do manicômio, nas práticas mais humanizadoras de inclusão, continuar-se-á ignorando que vivemos em uma sociedade que produz e reproduz a própria exclusão instituída porque ainda não conseguiu superar o manicômio que persiste em seu próprio imaginário.

Para tanto, é necessário que se compreenda urgentemente como os projetos de desinstitucionalização de fato têm se concretizado e como os usuários dos serviços substitutivos têm sido reconhecidos socialmente nos espaços que frequentam em suas comunidades. Em outras palavras, é preciso apreender como a condição de "portador de sofrimento mental" interfere ou possibilita que determinado indivíduo possa pertencer ao espaço público, e apreender se a condição de usuário dos serviços substitutivos de saúde mental possibilita que ele desenvolva sua alteridade e possa ser reconhecido como um sujeito de direito.

Afinal, é importante lembrar que embora a reforma psiquiátrica antimanicomial seja hegemônica atualmente no país nem todos os intelectuais e profissionais brasileiros concordam com os rumos que a política de nacional de saúde mental tem seguido. Os militantes da psiquiatria clássica seguem defendendo a legitimidade da retomada dos manicômios como modelo de tratamento dos transtornos mentais (Cf. Gentil, 2001).

Finalmente, é importante assinalar que embora a apreensão da história possa condenar algumas práticas da Psicologia Social no campo da saúde mental e evidenciar sua pactuação com a produção do discurso estigmatizador e naturalizador das desiguldades, a Psicologia Social Crítica pode contribuir à promoção de uma "revolução" psiquiátrica, uma vez que ela pode evidenciar como, nas condições sociais, políticas e econômicas a que estamos submetidos atualmente, os indivíduos têm (re)construído suas identidades, buscado emancipação a partir das condições de reconhecimento social oferecidas e enfrentado as políticas de Estado. Esse, sem sombra de dúvidas, é o nosso maior desafio, escapar de qualquer olhar saudosista do passado e de um futuro sem esperanças, assumindo com todas as consequências nossa capacidade de pensar o presente.

\section{REFERÊNCIAS}

Agamben, G. (2009). O que é o contemporâneo? $E$ outros ensaios. Chapecó: Argos.

Amarante, P. (1995). Novos Sujeitos, Novos Direitos: o Debate em Torno da Reforma Psiquiátrica. Cadernos de Saúde Pública. Rio de Janeiro, v. 11, n. 3, jul.-set., pp. 491-494 
Anderson, B. (2008). Comunidades Imaginadas: Reflexões sobre a origem e a difusão do nacionalismo. São Paulo, Companhia das Letras.

Aragaki, S. S. (2006). O aprisionamento de Selves em diagnósticos na área de Saúde Mental. Tese de Doutorado em Psicologia Social. São Paulo, PUC.

Berlink, M. T.; Magtaz, A. C. \& Teixeira, M. A reforma psiquiátrica brasileira: perspectivas e problemas. In, Revista Latinoamericana de Psicopatologia Fundamental. São Paulo: Editora Escuta, 2008. p.21-27.

Brandão, J. C. T. (1918). Elementos fundamentaes de psychiatria e clinica forense. Rio de Janeiro, Leite Ribeiro \& Maurillo.

Brasil. (1903). Decreto n. 1.132. Reorganiza a assistencia a Alienados. 22 de dez.

Brasil. (1961). Decreto $n^{0}$ 49.974-a. Regulamenta, sob a denominação de Código Nacional de Saúde, a Lei $n^{\circ} 2.312$, de 3 de setembro de 1954, de Normas Gerais Sôbre Defesa e Proteção da Saúde".

Brasil. (2002). Sistema Único de Saúde. Conselho Nacional de Saúde. Comissão Organizadora da III CNSM. Relatório Final da III Conferência Nacional de Saúde Mental. Brasília, Conselho Nacional de Saúde/Ministério da Saúde.

Brasil. (2003). Ministério da Saúde. Secretaria de Atenção à Saúde. Departamento de Ações Programáticas Estratégicas. Manual do Programa De Volta para Casa. Brasília, Ministério da Saúde.

Brasil. (2004). Lei n. 10.216. Dispõe sobre a proteção e os direitos das pessoas portadoras de transtornos mentais $e$ redireciona 0 modelo assistencial em saúde mental. 6 de abr. 2001. In: Brasil. Ministério da Saúde. Secretaria-Executiva. Secretaria de Atenção à Saúde. Legislação em Saúde Mental: 1990-2005. Brasília, Ministério da Saúde. 5 ed. ampliada.

Brasil. (2005). Conferência Regional de Reforma dos Serviços de Saúde Mental: 15 anos depois de Caracas. Brasília, Ministério da Saúde.

Brasil. (2007). Ministério da Saúde. Secretaria de Atenção à Saúde/DAPE. Coordenação Geral de Saúde Mental. Saúde Mental no SUS: acesso ao tratamento e mudança do modelo de atenção. Relatório de Gestão 2003-2006. Brasília.

Castoriadis, C. A. (1982). Instituição imaginária da sociedade. Rio de Janeiro: Paz e Terra. $6^{\mathrm{a}}$. Edição.

Basaglia, F. (2005). Escritos selecionados em saúde mental e reforma psiquiátrica. Rio de Janeiro: Garamond.

Dimenstein, M. Desinstitucionalizar é ultrapassar fronteiras sanitárias: o desafio da intersetorialidade e do trabalho em rede. In, Cad. Bras. Saúde Mental, vol. 1, jan-abr 2009. (CD-ROM)

Foucault, M. (2006). Problematização do Sujeito: Psicologia, Psiquiatria e Psicanálise. Tradução de Vera Lucia Avellar Ribeiro. Rio de Janeiro: Forense Universitária.

Foucault, M. (1991). História da loucura na Idade Clássica. São Paulo: Perspectiva. $3^{a}$. Edição.

Gentil, V. (2001). Editorial. Revista Brasileira de Psiquiatria, v. 23, n. 1, pp. 3-6.

Goffman, E. (1974). Manicômios, Prisões e Conventos. São Paulo: Perspectiva.

Habermas, J. (1990). Pensamento PósMetafísico: Estudos Filosóficos. Rio de Janeiro, Tempo Brasileiro.

Habermas, J. (2002). O Discurso Filosófico da Modernidade: Doze Lições. São Paulo, Martins Fontes.

Koda, M. Y. (2002). Da negação do manicômio à construção de um modelo substitutivo em saúde mental: o discurso de usuários e trabalhadores de um Núcleo de Atenção Psicossocial. Dissertação de Mestrado em Psicologia. São Paulo, USP.

Kyrillos Neto, F. (2007). Efeitos de circulação do discurso em serviços substitutivos de Saúde Mental: Uma perspectiva psicanalítica. Tese de Doutorado em Psicologia Social. PUCSP.

Laing, R. D. (1975). O eu dividido: Estudo existencial da sanidade e da loucura. Rio de Janeiro: Editora Vozes. $2^{a}$ edição.

Lavrador, M. C. C. (2007). A Psicologia e os desafios contemporâneos da Reforma Psiquiátrica. In, Jacó-Vilela, A. M. \& Sato, L. (orgs.) Diálogos em Psicologia Social. Porto Alegre: Editora Evangraf Ltda. p.361369.

Leal, E. (1994). A noção de cidadania como eixo da prática clínica: uma análise do programa de saúde mental de Santos. 
Dissertação de Mestrado. Rio de Janeiro, Instituto de Medicina Social da UERJ.

Lima, A. F. (2010). Metamorfose, anamorfose e reconhecimento perverso: a identidade na perspectiva da Psicologia Social Crítica. São Paulo: EDUC.

Machado, L. D. \& Lavrador, M. C. C. Loucura e Subjetividade. In, Machado, L. D. \& Lavrador, M. C. C. (orgs.) Texturas da psicologia: subjetividade e política no contemporâneo. São Paulo: Casa do Psicólogo, 2001. p.45-58.

Martín-Baró, I. (1984). Guerra y Salud Mental. In, Estúdios Centroamericanos. n. 429/430.

Nader, R. M. (1990). Psicologia e Transformação: os caminhos para a prática psi. Tese de doutorado em Ciências. São Paulo, PUC.

Nina Rodrigues, R. (1901). O alienado no direito civil brasileiro: apontamentos medicolegaes ao projecto de código civil. Bahia, Imprensa Moderna.

Passos, A. C. B. Utilização de Psicofármacos entre os usuários da Atenção Primária do município de Maracanaú, Ceará. Dissertação de Mestrado em Ciências Farmacêuticas. UFC, 2008.

Postel, J. \& Quétel, C. (Orgs.) (2000). Nueva Historia de la Psiquiatría. México, Fondo de Cultura Econômica. 2 ed.

Queiroz, I. S. (2005). Adoção de ações de redução de danos direcionados aos usuários de drogas: concepções e valores de equipes do programa de saúde da família. Dissertação de Mestrado em Psicologia. UFMG.

Rotelli, F. (2006). Empresa Social: construindo sujeitos e direitos. In, Amarante, P. (Org.) Ensaios: subjetividade, saúde mental, sociedade. Rio de janeiro: Editora Fiocruz. p. 301-306. 1a. Reimp.

Sardigursky, D. \& Tavares, J. L. Algumas considerações sobre 0 processo de desinstitucionalização. In, Rev. Latinoamericana de Enfermagem. v.6, n.2, abril 1998. p.23-27.

Szasz, T. S. (1977). Ideologia e Doença Mental: ensaios sobre a desumanização psiquiátrica do homem. Rio de Janeiro: Zahar Editores.
Szasz, T. S. (1979). O mito da doença mental: Fundamentos de uma Teoria da Conduta Pessoal. Rio de Janeiro: Zahar Editores.

Szasz, T. S. (1984). A fabricação da Loucura: um estudo compara- tivo entre a Inquisição e o movimento de Saúde Mental. Rio de Janeiro, Guanabara. 3 ed.

Szasz, T. S. (1994). Cruel Compaixão. Campinas, Papirus.

Szasz, T. S. (2008). Psychiatry: the Science of Lies. Syracuse, New York: Syracuse University Press.

Vasquez, A. S. (1977). Filosofia da Práxis. Rio de Janeiro, Paz e Terra. 2 ed.

Yahn, M. (1955). Higiene Mental. São Paulo, Edigraf. 